\title{
Transcriptional activation of USP16 gene expression by NFKB signaling
}

\author{
Shou Yang ${ }^{1 \dagger}$, Juelu Wang ${ }^{2+}$, Shipeng Guo ${ }^{1 \dagger}$, Daochao Huang ${ }^{1 \dagger}$, Isabel Bestard Lorigados ${ }^{2}$, Xing Nie $^{1}$, Dandan Lou',
} Yanhua Li $i^{1}$, Mingjing Liu', Yu Kang ${ }^{1}$, Weihui Zhou ${ }^{1 *}$ and Weihong Song ${ }^{1,2^{*}}$ (D)

\begin{abstract}
Ubiquitin Specific Peptidase 16 (USP16) has been reported to contribute to somatic stem-cell defects in Down syndrome. However, how this gene being regulated is largely unknown. To study the mechanism underlying USP16 gene expression, USP16 gene promoter was cloned and analyzed by luciferase assay. We identified that the $5^{\prime}$ flanking region ( $-1856 \mathrm{bp} \sim+468 \mathrm{bp}$ ) of the human USP16 gene contained the functional promotor to control its transcription. Three bona fide NFKB binding sites were found in USP16 promoter. We showed that p65 overexpression enhanced endogenous USP16 mRNA level. Furthermore, LPS and TNFa, strong activators of the NFKB pathway, upregulated the USP16 transcription. Our data demonstrate that USP16 gene expression is tightly regulated at transcription level. NFKB signaling regulates the human USP16 gene expression through three cis-acting elements. The results provide novel insights into a potential role of dysregulation of USP16 expression in Alzheimer's dementia in Down Syndrome.
\end{abstract}

Keywords: Down syndrome, USP16, NFKB, Transcriptional regulation, Promotor

\section{Introduction}

Down syndrome (DS) is a complex developmental disorder caused by genetic defects, leading to intellectual and developmental disabilities. It is a result of complete or partial trisomy of chromosome 21 [1, 2]. Individuals with DS therefore have three copies of 161 known protein-encoding genes. The phenotypes of DS are believed to be related with abnormal gene expression and functions due to the extra copy of the genes on chromosome $21[3,4]$, and the DS patients invariably develop Alzheimer's disease (AD)-related neuropathology [5-10]. Although a few candidate genes have been linked to the spectrum of disorders associated with DS [11-16], it is unclear that how trisomy of specific genes contributes to the disease.

The human USP16 gene is mapped on chromosome 21 and triplicated in DS. USP16 gene contains 3 mRNA transcripts which share the same start codon, stop

\footnotetext{
*Correspondence: zhouweihui@aliyun.com; weihong@mail.ubc.ca

†Shou Yang, Juelu Wang, Shipeng Guo and Daochao Huang contributed equally to this work.

${ }^{1}$ Chongqing City Key Lab of Translational Medical Research in Cognitive Development and Learning and Memory Disorders, and Ministry of Education Key Lab of Child Development and Disorders, Children's Hospital of Chongqing Medical University, Chongqing 400014, China Full list of author information is available at the end of the article
}

codon, and translation frame. USP16 has been reported to contribute to the somatic stem-cell defects in DS and reduce the self-renewal of multiple somatic stem cells [17], suggesting that some of the pathological features associated with DS may result from a stem-cell imbalance due to overexpression of USP16. It was first identified as a histone $\mathrm{H} 2 \mathrm{~A}$ specific deubiquitinase that regulates cell cycle progression and gene expression in human cells [18]. This deubiquitinating enzyme, USP16, removes the ubiquitin protein from $\mathrm{H} 2 \mathrm{~A}-\mathrm{K} 119$, and upregulates the transcription of the Ink4a locus [17]. The Ink4a locus encodes the $\mathrm{p} 16^{\text {Ink4a }}$ and the $\mathrm{p} 19^{\mathrm{Arf}}$ genes, which are important members participating in self-renewal and senescence pathways. It was reported that USP16 was upregulated in response to DNA damage, and the upregulation of its expression was HECT and RCC1-like domain-containing protein 2 (HERC2)dependent [19]. Furthermore, USP16 was shown to regulate embryonic stem cell gene expression and hematopoietic stem cell function [20,21]. A recent study reported that USP16 was involved in cancer, and its downregulation promoted hepatocellular carcinoma cells growth [22]. The converging lines of evidence shed light on USP16 's functions, but the transcriptional regulation of USP16 gene is largely unknown.

(c) The Author(s). 2019 Open Access This article is distributed under the terms of the Creative Commons Attribution 4.0 International License (http://creativecommons.org/licenses/by/4.0/), which permits unrestricted use, distribution, and 
NFkB signaling pathway plays an important role in the gene regulation [23-25] and is associated with inflammation [26], oxidative stress [27], and apoptosis [28]. The mammalian NFkB family consists of five members, including NFкB1 (p50), NFкB2 (p52), RelA (p65), RelB, and C-Rel [29]. These members form various homo- or heterodimeric complexes. Activation of NFkB is tightly controlled by an inhibitory subunit, known as the inhibi-

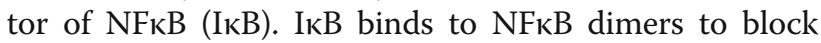
their nuclear localization sequences, thus NFkB dimers are retained within the cytoplasm [30]. Once cells are stimulated by activators, such as tumor necrosis factor- $\alpha$ (TNF $\alpha$ ) and lipopolysaccharide (LPS) [31], IKB is phosphorylated by IKB kinase (IKK) complex, making itself being degraded by ubiquitin-proteasome pathway [32]. Then NFkB dimers are released and translocated into the nucleus, where they regulate the transcription of the NFKB target genes [29].

Previous studies have shown that NFKB plays essential roles in cell cycle progression [33], senescence [34], DNA damage repair [35], maintenance of stem cells pluripotency [36] and cancer. In the present study, we aim to elucidate how USP16 gene expression is regulated and the role of NFKB in USP16 gene regulation. We cloned and functionally analyzed the human USP16 gene promoter region. We showed that the USP16 gene promoter contained functional cis-acting $\mathrm{NFK}_{\mathrm{B}} \mathrm{B}$ binding sites. By using EMSA, we identified three bona fide binding sites, through which NFKB signaling regulates USP16 gene transcription. p65 overexpression was shown to increase the endogenous USP16 mRNA level and the activators of the NFKB pathway, including LPS and TNF $\alpha$, also upregulated the USP16 transcription. By knocking out p65 in mice embryonic fibroblasts, the effects of TNF $\alpha$ on upregulating USP16 transcription was abolished.

\section{Materials and methods \\ Primers and plasmids construction}

The 5' flanking region of the human USP16 gene was amplified by polymerase chain reaction (PCR) from human genomic DNA. The primers were designed with restriction enzymes sites compatible with multi-cloning sites of vector pGL4.10 (Promega). The pGL4.10 vector lacks eukaryotic promoter and enhancer sequences upstream of a reporter luciferase gene. We first cloned the longest $2324 \mathrm{bp}(-1856 \mathrm{bp} \sim+468 \mathrm{bp})$ promotor region into pGL4.10 at the XhoI and HindIII sites to generate pUSP16-A. Then, promotor deletion assays were conducted as previously described [25, 37]. Briefly, a series of deletion fragments were amplified by using pUSP16-A as the template and sub-cloned into pGL4.10 at proper restriction enzymes sites. All used primers were listed in Additional file 1.
Cell culture, luciferase assays, and transfection Human embryonic kidney 293 (HEK293) (RRID:CVCL_ 0045) and human neuroblastoma SH-SY5Y cell lines (RRID:CVCL_0019) were cultured in Dulbecco's modified Eagle's medium (DMEM, Gibco) containing 10\% fetal bovine serum (FBS, Gibco). Wildtype (WT) mouse embryonic fibroblasts (MEFs) and p65 knockout (KO) MEFs were maintained in DMEM supplemented with $15 \%$ FBS, $\beta$-mercaptoethanol, and ESGRO (LIF) [24]. All cells were maintained in a $37^{\circ} \mathrm{C}$ incubator containing $5 \% \mathrm{CO}_{2}$. For luciferase assays, pCMV-Rluc (Promega) was co-transfected with $\mathrm{p} U S P 16$-related promoter plasmids as a control to normalize the transfection efficiency. Specifically, $270 \mathrm{ng}$ pUSP16-related promoter plasmids and $30 \mathrm{ng}$ pCMV-Rluc were cotransfected into each well of a 48 well-plate by using $0.9 \mu$ l Lipofectamine- ${ }^{\mathrm{r}} 2000$ reagent (Invitrogen). Cells were harvested $24 \mathrm{~h}$ after transfection and lysed with $60 \mu \mathrm{l} 1 \times$ passive lysis buffer (Promega) per well. Activities of the Firefly and Renilla luciferases from the same sample were sequentially assayed by a luminometer (GloMax 20/20) following the protocol of the dual-luciferase reporter assay system (Promega, E1910). The Firefly luciferase activity was normalized by the Renilla luciferase activity and the results reflected the relative promoter activity. For RNA extraction analysis, $4 \mu \mathrm{g}$ plasmid DNA was transfected by $12 \mu$ l Lipofectamine ${ }^{\text {tix }} 2000$ reagent per well of a 6 well-plate.

\section{Electrophoretic mobility shift assay (EMSA)}

EMSA was performed as previously described [38]. To obtain NFKB-enriched nuclear extract, HEK293 cells were transfected with the p65 expression plasmid (pMTF-p65) for $24 \mathrm{~h}$. Nuclear protein was extracted by using NE-PER ${ }^{\mathrm{Tu}}$ nuclear and cytoplasmic extraction reagents (Thermo Scientific) according to the manufacturer's instructions. Five oligonucleotides probes were labeled with IR700 dye (Bioneer Corporation) and annealed with corresponding anti-sense oligonucleotides to generate double-stranded probes at a final concentration of $0.01 \mathrm{pmol} / \mu \mathrm{l}$. Among them, USP16 $3 \mathrm{x}$ NFkB contained three NFkB cis-acting elements, including NFкB2, NFкB3, and NFкB4. USP16-NFкB1,

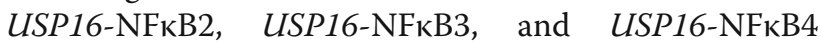
oligonucleotide had a corresponding sequence. For competition experiments, $2 \mu \mathrm{l}$ of nuclear extract was incubated with $0.01 \mathrm{pmol} / \mu \mathrm{l}$ of labeled probes and $100 \times(1 \mathrm{pmol} / \mu \mathrm{l})$ unlabeled competition probes for 20 min at room temperature. For the supershift assay, monoclonal anti-NFkB p65 antibody (Cell Signaling, 8424 s) was added. The reaction mixtures were separated on a $4 \%$ Tris-glycine-EDTA gel for $70 \mathrm{~min}$ at $70 \mathrm{~V}$ in darkness. The gel was scanned using LI-COR Odyssey (LI-COR Biosciences) at a wavelength of 700 
$\mathrm{nm}$. The sequences of the oligonucleotides were listed in Additional file 1.

\section{LPS and TNFa treatment}

LPS (Sigma, L4516) was reconstituted in DMEM and further diluted to a final concentration of $50 \mathrm{ng} / \mathrm{ml}$, while TNFa (Sigma, H8916) was reconstituted in sterile phosphate buffered saline (PBS) containing $0.1 \%$ endotoxin-free recombinant human serum albumin at a final concentration of $10 \mathrm{ng} / \mathrm{ml}$. For qRT-PCR, HEK293 and SH-SY5Y cells were exposed to LPS and TNF $\alpha$ at the proper concentration for $24 \mathrm{~h}$ and then lysed for RNA extraction. For RT-PCR, MEF WT and p65 KO cells were treated with $5 \mathrm{ng} / \mathrm{ml}$ TNF $\alpha$ for $24 \mathrm{~h}$.

\section{qRT-PCR}

Total RNA was extracted from cells using TRI reagent (BioTeke, RP1202), and quantified with Nanodrop 2000 (Thermo Fisher Scientific, Waltham, MA, USA). PrimeScript $^{\text {ma }}$ RT reagent Kit (Takara, RR037A) was used to synthesize the first-strand cDNA from an equal amount of various RNA samples according to the manufacturer's instructions. qRT-PCR was performed by using SYBR ${ }^{\circ}$ Premix Ex Taq ${ }^{\text {TI }}$ II (Takara, RR820A) and the PCR program included one initial denaturation step at $95^{\circ} \mathrm{C}$ for $3 \mathrm{~min}, 39$ cycles of $95^{\circ} \mathrm{C}$ for $10 \mathrm{~s}, 58^{\circ} \mathrm{C}$ for $30 \mathrm{~s}$, and $72^{\circ} \mathrm{C}$ for $30 \mathrm{~s}$ (Bio-Rad CFX96). Glyceraldehyde 3-phosphate dehydrogenase (GAPDH) was used as an endogenous control. Primers used in this assay were listed in Additional file 1. Amplification efficiency of those primers were checked by standard curve method, with an E value around $100 \%\left(R^{2}>0.998\right)$. The relative expression of mRNA was calculated with the $2^{-\Delta \Delta T}$ method. Each sample was triplicated. qRT-PCR data were analyzed and converted to relative fold changes. Additionally, total RNA was extracted from MEF WT or p65 KO cells by TRIzol reagent (Invitrogen). Thermoscript ${ }^{\mathrm{Tm}}$ SuperScript IV first-strand synthesis system (Invitrogen) was applied to amplify the first-strand cDNA by using $1.5 \mu \mathrm{g}$ of total RNA as the template and then the newly synthesized cDNA was used as the template to perform PCR by Taq DNA polymerase. A pair of primers to amplify a $150 \mathrm{bp}$ region of mice USP16 gene was as follows: forward, $5^{\prime}$ ctgccaagactgtaagactgac, and reverse, 5' - ggtgtcgtgtagtgcttcaag. Additionally, a pair of primers for amplifying a $205 \mathrm{bp}$ fragment of mouse GAPDH gene coding sequence was as follows: forward, 5' - ggatttggtcgtattggg, and reverse, 5'ggaagatggtgatgggatt. All samples were analyzed on $2.5 \%$ agarose gels.

\section{Statistical analyses}

Three or more independent experiments were performed. All results were presented as mean \pm the standard error of the mean (SEM) and 2-tailed Student's $t$ test was used to analyze the difference between two groups.
One-way Analysis of variance (ANOVA) was applied to analyze the data in Fig. 2 and multiple comparison tests were conducted by post-hoc Turkey's method. Statistical analysis in Fig. 3 and Fig. 5e-f was performed by twoway ANOVA followed by post-hoc Turkey's multiple comparisons test. $p<0.05$ was considered as statistically significant.

\section{Results}

\section{Cloning of the human USP16 promoter}

The human USP16 gene is mapped on chromosome 21, at 21q21.3. It has three mRNA transcripts which share the same start codon, stop codon, and translation frame. Transcript 1 and 3 encode the same isoform a and transcript 2 encodes isoform $b$. Transcripts 3 is the longest one which contains all the 19 exons, while the other two lack Exon 2. The only difference between transcript 1 and transcript 2 is that the later is shorter and lacks the first codon "CAG" in Exon 7 (Fig. 1a). Human genomic DNA were extracted from HEK293 cells and a $2324 \mathrm{bp}$ $5^{\prime}$ flanking region of the USP16 gene was amplified by PCR. The human USP16 gene has a complex transcriptional machinery as suggested by the results from a computer-based transcription factor binding site search using Genomatix and TFSearch. The human USP16 gene promoter was shown to contain several putative regulatory elements, such as MAF and AP1 related factors (AP1R), NFKB, hypoxia-inducible factor (HIF), nuclear factor of activated T-cells (NFAT), cAMPresponsive element binding proteins (CREB), and Ying Yang 1 (YY1) (Fig. 1b). There are 4 putative NFkB binding sites spanning a wide region of USP16 gene promoter in our predication results and $\mathrm{NF}_{\kappa} \mathrm{B}$ signaling pathway is an essential player in the inflammatory response, which has been recognized as a factor to facilitate the pathogenesis of DS and AD phenotypes in DS patients [39]. Therefore, we mainly focused on NFкB signaling pathway in the following experiments.

\section{Functional analysis of the human USP16 gene promoter}

To determine the functional promoter region of the human USP16 gene, we cloned a 2324 bp 5' flanking region of the USP16 gene into a promoter-lacking vector pGL4.10 to generate pUSP16-A ( $-1856 \mathrm{bp}$ to $+468 \mathrm{bp}$ ) plasmid. The luciferase activities of cells transfected with this plasmid largely rely on the presence of a functional promoter upstream of a luciferase gene. The plasmid pUSP16-A was transfected into HEK293 cells, and luciferase activity was measured by a GloMax 20/20 Luminometer to examine its promoter activity. Compared with cells transfected with an empty vector pGL4.10, pUSP16-A showed a significant increment of luciferase activity (84.48 \pm 4.55RLU, $p<0.0001$ ) (Fig. 2c). This result indicates 


\section{CAGAGAAAG...}

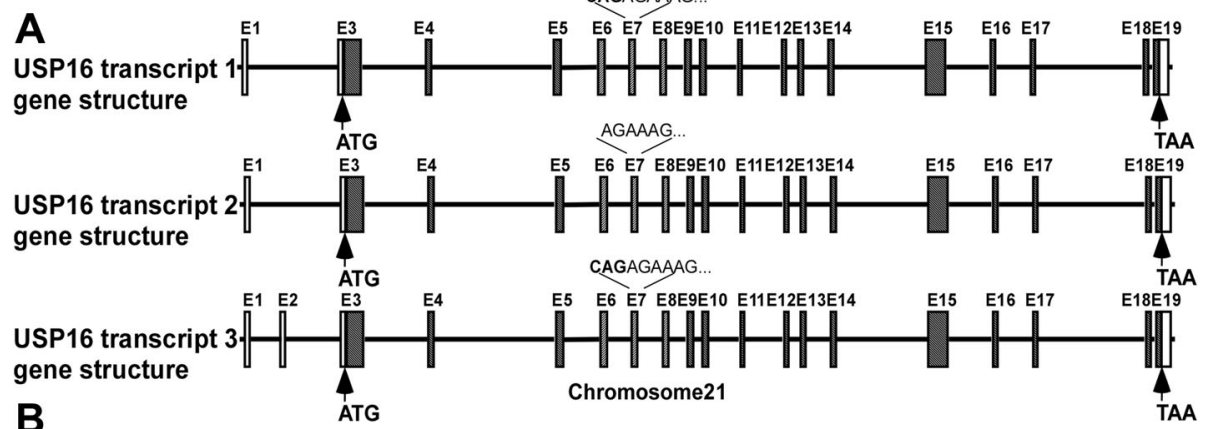

B

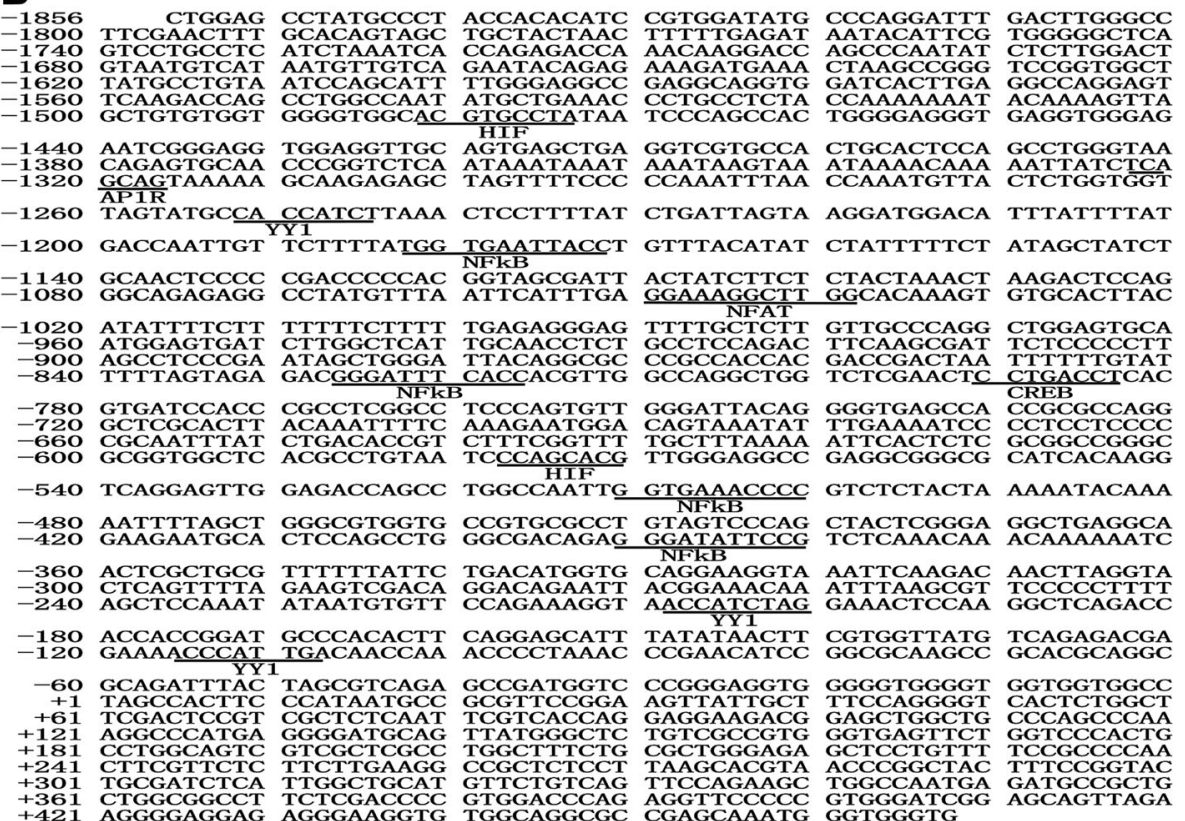

Fig. 1 Sequence of the human USP16 gene promotor. a The genomic structure of the human USP16 gene on Chromosome 21. E stands for exon. USP16 consists of 19 exons. ATG is the translation start codon located in E3 and TAA is the stop codon. $\mathbf{b}$ The nucleotide sequence of the human USP16 gene promotor. A 2324 bp fragment of the 5' flanking region of the human USP16 gene was cloned from HEK293 genomic DNA. The Thymine +1 represents the first base of transcription in E1. The putative transcription factor binding sites are underlined in bold

that the $2324 \mathrm{bp}$ fragment contains the functional promoter region of the human USP16 gene.

To identify the regulatory elements in the USP16 promotor region, a series of deletion fragments within pUSP16-A was generated (Fig. 2a). The luciferase assays of these deletion plasmids were performed. The results indicated that pUSP16-B $\quad(-1325 \mathrm{bp} \sim+468 \mathrm{bp}, \quad 75.91 \pm 4.40 \mathrm{RLU} ; \quad p>$ 0.9999), pUSP16-C (-653 bp + 468 bp, $50.98 \pm 4.74 R L U$; $p=0.1065)$, and $\mathrm{p} U S P 16-\mathrm{D}(-200 \mathrm{bp} \sim+468 \mathrm{bp}, 55.21 \pm$ 3.57 RLU; $p=0.2514$ ) have no significant changes of luciferase activities when compared with pUSP16-A ( -1856 bp to $+468 \mathrm{bp}, 84.48 \pm 4.55 \mathrm{RLU})$. A series of 3'end deletion plasmids was constructed and transfected into HEK293 cells. Luciferase activities of these plasmids showed that a $41 \mathrm{bp}$ deletion (pUSP16-E, - $200 \mathrm{bp} \sim+427 \mathrm{bp}, 172.13 \pm 7.16 \mathrm{RLU}$ ) from pUSP16-D (- $200 \mathrm{bp} \sim+468 \mathrm{bp}, \quad 55.21 \pm 3.57 \mathrm{RLU})$ greatly increased promotor activity $(p<0.0001)$, indicating that there are negative regulatory elements located in this region. A further $42 \mathrm{bp}$ deletion (pUSP16-F, - $200 \mathrm{bp} \sim+$ $385 \mathrm{bp}, 95.36 \pm 5.98 \mathrm{RLU}$ ) significantly reduced promotor activity when compared to pUSP16-E ( $200 \mathrm{bp} \sim+427 \mathrm{bp}$, $172.13 \pm 7.16 \mathrm{RLU})(p<0.0001)$, while deletion plasmids pUSP16-G $(-200 \mathrm{bp} \sim+261 \mathrm{bp}, 68.06 \pm 6.89 \mathrm{RLU} ; \quad p=$ $03525)$ and $\mathrm{p} U S P 16-\mathrm{H} \quad(-200 \mathrm{bp} \sim+150 \mathrm{bp}, 84.89 \pm$ 1.88RLU; $p=0.9995)$ did not show significant changes to that of pUSP16-F ( $200 \mathrm{bp} \sim+385 \mathrm{bp}, 95.36 \pm 5.98 \mathrm{RLU})$. However, a further $20 \mathrm{bp}$ deletion (pUSP16-I, $-200 \mathrm{bp} \sim+$ $130 \mathrm{bp}, 266.32 \pm 7.80 \mathrm{RLU})$ from $\mathrm{p} U S P 16-\mathrm{H}(-200 \mathrm{bp} \sim+$ $150 \mathrm{bp})$ largely enhanced promotor activity $(p<0.0001)$, indicating that the $20 \mathrm{bp}$ region contains negative regulatory elements.

Further deletion analysis found that a $20 \mathrm{bp}$ deletion from pUSP16-I ( $200 \mathrm{bp} \sim+130 \mathrm{bp}, 266.32 \pm 7.80 \mathrm{RLU})$ to pUSP16-J (- $200 \mathrm{bp} \sim+110 \mathrm{bp}, 201.22 \pm 12.10 \mathrm{RLU}, \quad p<$ $0.0001)$ and a $12 \mathrm{bp}$ deletion from pUSP16-J $(-200 \mathrm{bp} \sim+$ $110 \mathrm{bp})$ to $\mathrm{p} U S P 16-\mathrm{N} \quad(-200 \mathrm{bp} \sim+98 \mathrm{bp}, \quad 100.74 \pm$ 


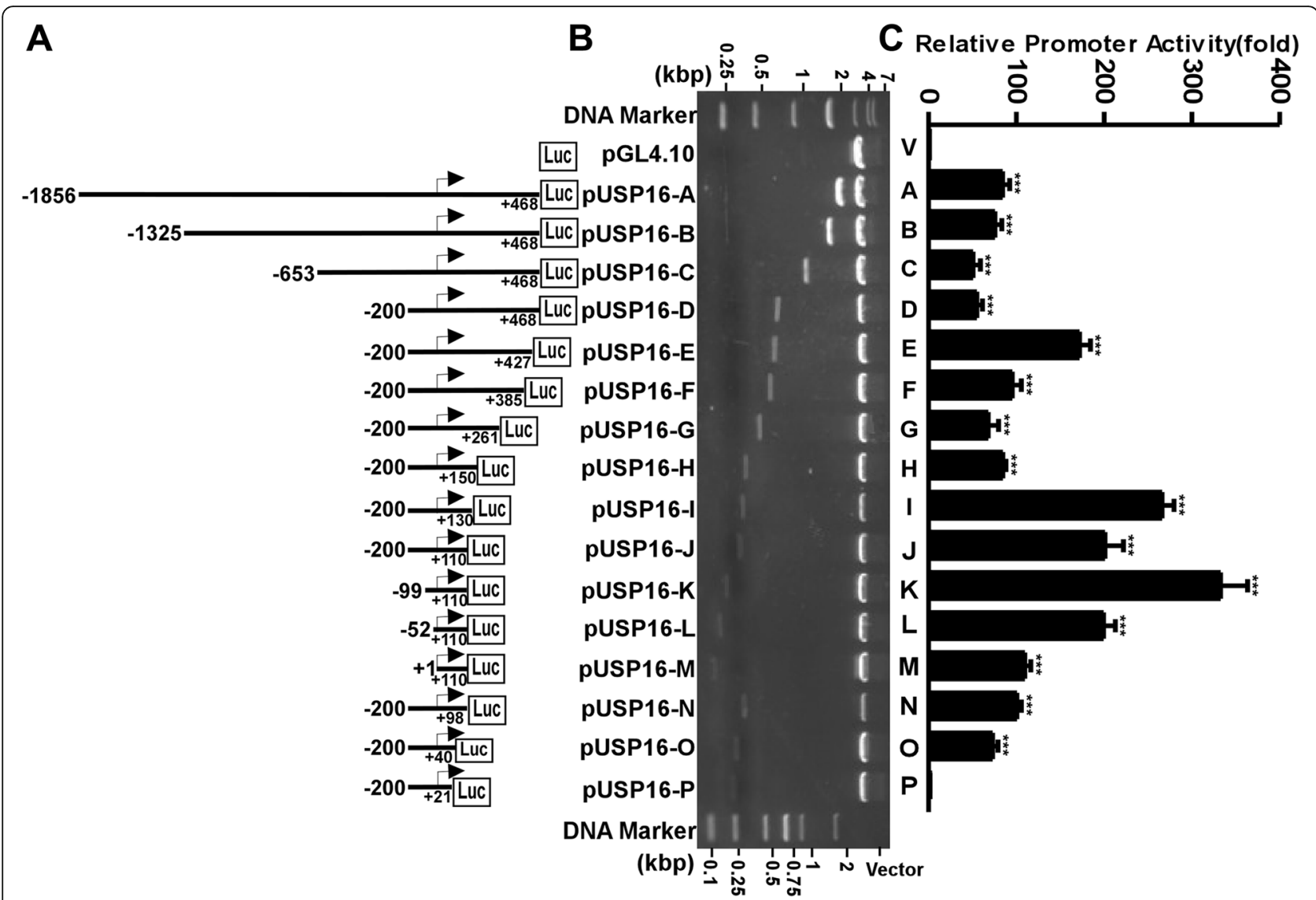

Fig. 2 Deletion analysis of the human USP16 gene promoter. a Schematic diagram of the human USP16 deletion promoter constructs in pGL4.10 vector. Arrow shows the direction of transcription. The numbers represent the start and end points for each construct. $\mathbf{b}$ The deletion plasmids were confirmed by restriction enzyme digestion, and the digested samples were analyzed on a 1.0\% agarose gel. The vector size is $4.2 \mathrm{~kb}$; USP16 promoter fragment size ranges from 0.11 to $2.3 \mathrm{~kb}$. The sequences of the inserts were further confirmed by sequencing. c The promoter plasmids were co-transfected with pCMV-Luc into HEK293 cells. After $24 \mathrm{~h}$ transfection, the cells were harvested and luciferase activity was measured with a luminometer and presented in relative luciferase units (RLU). The pCMV-Luc luciferase activity was used to normalize for transfection efficiency. The values represent means \pm SEM. $n=3,{ }^{* * *} p<0.001$ by one-way ANOVA test followed by post-hoc Turkey's test. Comparisons were made between all USP16 promoter reporter plasmids and the empty pGL4.10 as a negative control

2.94RLU, $p<0.0001)$ substantially reduced promotor activity, while a $48 \mathrm{bp}$ deletion from pUSP16-N (-200 $\mathrm{bp} \sim+98 \mathrm{bp})$ to $\mathrm{p} U S P 16-\mathrm{O}(-200 \mathrm{bp} \sim+40 \mathrm{bp}, 73.13 \pm$ 3.51RLU) did not significantly change the promoter activity $(p=0.3357)$. However, a further $19 \mathrm{bp}$ deletion from pUSP16-O (- $200 \mathrm{bp} \sim+40 \mathrm{bp})$ to pUSP16-P (- $200 \mathrm{bp} \sim+$ $21 \mathrm{bp}, 1.74 \pm 0.07 \mathrm{RLU})$ almost abolished promotor activity $(p<0.0001)$. These results showed that $+40 \mathrm{bp}$ was the proper 3' boundary of the USP16 promotor region. Since we found pUSP16-J (-200 bp +110 bp, $201.22 \pm$ 12.10RLU) still had a high promotor activity compared with the empty vector pGL4.10 $(p<0.0001)$, pUSP16-J was chosen to investigate the effect of 5 'end on promotor activity. A series of 5'end deletion plasmids was constructed and transfected into HEK293 cells. Luciferase activity showed that a $101 \mathrm{bp}$ deletion (pUSP16-K, - 99 $\mathrm{bp} \sim+110 \mathrm{bp}, 332.87 \pm 17.59 \mathrm{RLU})$ from pUSP16-J $(-200$ $\mathrm{bp} \sim+110 \mathrm{bp})$ increased USP16 promotor activity $(p<$
0.0001), while a $47 \mathrm{bp}$ deletion (pUSP16-L, $-52 \mathrm{bp} \sim+$ $110 \mathrm{bp}, 199.65 \pm 7.69 \mathrm{RLU})$ from $\mathrm{p} U S P 16-\mathrm{K}(-99 \mathrm{bp} \sim+$ $110 \mathrm{bp})$ decreased USP16 promotor activity $(p<0.0001)$ and a further $52 \mathrm{bp}$ deletion (pUSP16-M, + $1 \mathrm{bp} \sim+110$ bp, $109.72 \pm 3.88$ RLU) from pUSP16-L $(-52 \mathrm{bp} \sim+110$ $\mathrm{bp})$ reduced USP16 promotor activity $(p<0.0001)$. Taken together, our data illustrate that the promoter region from $+1 \mathrm{bp}$ to $+40 \mathrm{bp}$ has the minimal promoter activity required for basal transcription and various cis-acting regulatory elements are located in the $5^{\prime}$ flanking region of USP16 gene.

NFKB upregulates the human USP16 gene promotor activities

Computer-based transcription factor binding site analysis revealed four putative $\mathrm{NF}_{\kappa} \mathrm{B}$ cis-acting elements in the $1793 \mathrm{bp}(-1325 \mathrm{bp} \sim+468 \mathrm{bp})$ promoter region of the human USP16 gene (Fig. 1b). To determine whether 
NFKB signaling regulates USP16 gene transcription by interacting with these putative $\mathrm{NF}_{\kappa} \mathrm{B}$ cis-acting elements, the effects of $\mathrm{NFKB}$ overexpression on the promoter activity of the $1793 \mathrm{bp}$ region were examined. Four human USP16 promoter deletion constructs, pUSP16-N1, -N2, $-\mathrm{N} 3$, and -N4, were cloned into pGL4.10 vector, with sequential elimination of one upstream putative NFKBbinding element (Fig. 3a, b). We used a dual-luciferase reporter assay to examine the USP16 promoter activity in HEK293 cells overexpressed with NFkB p65 expression plasmid (pMTF-p65) or empty vector (pMTF). Compared with empty vector pMTF, NFkB p65 expression plasmid co-transfecting with pUSP16-N1, pUSP16$\mathrm{N} 2$, pUSP16-N3, and pUSP16-N4 resulted in enhanced luciferase activities to about 2.69, 2.51, 2.24, and 2.04 folds, respectively $(p<0.0001)$ (Fig. 3c). Furthermore, if comparing the luciferase activities among pUSP16-N1, $-\mathrm{N} 2,-\mathrm{N} 3$, and N4 plasmids after NFkB p65 overexpression, the statistical significance was observed between $\mathrm{p} U S P 16-\mathrm{N} 1$ vs. $\mathrm{p} U S P 16-\mathrm{N} 3(p=0.0009), \mathrm{p} U S P 16-\mathrm{N} 1$ vs. $\mathrm{p} U S P 16-\mathrm{N} 4(p<0.0001)$ and $\mathrm{p} U S P 16-\mathrm{N} 2$ vs. $\mathrm{p} U S P 16-\mathrm{N} 4$ $(p=0.0004)$. These suggested that deletion of binding site 2 and 3 had substantial impact on NFkB p65's role in upregulating USP16 gene promoter. In SH-SY5Y cells, similar results were observed for NFkB p65's effects on increasing the activities of USP16 gene promoter $(p<$ 0.0001) (Fig. 3d). To further confirm the involvement of p65 in regulating USP16 gene promoter, two more deletion constructs, pUSP16-N5 and -N6, were generated. Both pUSP16-N5 and -N6 plasmids do not contain any putative NFKB-binding element (Fig. 3a, b). Unexpectedly, the promoter activity of pUSP16-N5 was still significantly increased to 8.67 folds in HEK cells $(p<$ $0.0001)$ and to 1.85 folds in SH-SY5Y cells $(p=0.0005)$ by $\mathrm{p} 65$ overexpression compared with the empty vector transfection. A further deletion fragment, pUSP16-N6, was completely abolished the effect of p65 overexpression on affecting its promoter activity (Fig. 3e, f), suggesting a non-canonical NFKB binding site sequence located in pUSP16-N5 was indirectly affected by p65 [40]. Taken together, these results demonstrate that NFkB p65 up-regulates human USP16 promoter activity.

\section{USP16 promoter activity is regulated through three NFKB} binding elements

To investigate which putative $\mathrm{NF}_{\kappa} \mathrm{B}$ binding elements of USP16 interact with $\mathrm{NFK}_{\mathrm{K}} \mathrm{B}$ p65, we performed EMSA to determine whether four putative NFKB cisacting elements physically bind to NFKB p65. We synthesized NFkB consensus oligonucleotides end-labeled with IR700 dye as probes and four oligonucleotides (USP16 NFKB 1-4) containing each NFkB cis-acting element as competitors. Labelled NFKB consensus probes were visualized as a heavy band on the bottom of the gel (Fig. 4b, lane 1), and a shift band was formed after the addition of the p65-enriched nuclear extracts (Fig. 4b, lane 2), suggesting DNA- protein complex formation. Moreover, the shift band was abolished when $\mathrm{NF} \kappa \mathrm{B}$ consensus, $100 \times$ USP16 NFKB2, or $200 \times$ USP16 NFkB2 (Fig. 4b; lanes 3, 5, 6) was applied, but not for NFkB mutant or USP16 NFkB2 mutant (Fig. 4b; lanes 4, 7). Addition of anti-NFkB p65 antibody resulted in a slower migrating super shifted band (Fig. 4b, lane 8), confirming the existence of $\mathrm{NFKB}$ in the complex formation. Similar results were seen in USP16 NFkB3 group (Fig. 4c) and USP16 NFKB4 group (Fig. 4d), but not in USP16 NFKB1 group (Fig. 4a). The data suggests that the second, third and the fourth NFKB-binding elements in USP16 gene are able to interact with NFkB p65.

To further confirm these results, we performed additional EMSA with the three $\mathrm{NFK}_{\mathrm{B}}$ cis-acting elements (USP16 NFkB2,3,4) end-labeled with IR700 dye as probes. Each probe contained a single putative $\mathrm{NF}_{\kappa} \mathrm{B}$ cis-acting site. A shifted protein-DNA complex band was detected after incubating USP16 NFkB2 probe with NFkB-enriched nuclear extract (Fig. 4e, lane 2). This shifted band was abolished by addition of $100 \times$ USP16 $\mathrm{NF \kappa B2}$ or NFkB consensus oligonucleotide (Fig. 4e; lanes 3, 5), but not USP16 NFkB2 mutant or NFkB mutant (Fig. 4e; lanes 4, 6). Super EMSA was performed to further confirm the existence of $\mathrm{NFKB}$ elements in the USP16 NFKB2 probe. Addition of anti-NFKB p65 antibody resulted in a slower migrating super shifted band (Fig. 4e, lane 7), Similar results were also obtained for USP16 NFkB3 (Fig. 4f), USP16 NFkB4 (Fig. 4g). In addition, we synthesized a single probe (USP16 3x $\mathrm{NFkB}$ ) containing three $\mathrm{NF \kappa B}$ cis-acting elements and gained similar results (Fig. 4h). The data demonstrated that the second, third, and the fourth $\mathrm{NF}_{\mathrm{K}} \mathrm{B}$ binding elements in USP16 gene interact with NFKB p65.

\section{Activation of NFKB signaling increases the human USP16 gene transcription}

To examine whether NFkB affects the endogenous gene transcription, qRT-PCR was conducted to measure the endogenous USP16 mRNA level. Overexpression of NFKB markedly upregulated endogenous mRNA level of the USP16 gene compared to the control group (1.52-fold, $p<0.0001$ ) (Fig. 5a). LPS and TNF $\alpha$ are strong activators of $\mathrm{NFKB}_{\mathrm{K}}$ signaling pathway. To explore whether $\mathrm{NFKB}$ binding elements in the human USP16 promoter mediate the inflammatory effect on USP16 transcription, we examined USP16 mRNA levels after LPS and TNF $\alpha$ treatment. HEK293 cells or SH-SY5Y cells were treated with LPS (50 $\mathrm{ng} / \mathrm{ml})$ or TNFa $(10 \mathrm{ng} / \mathrm{ml})$ for $24 \mathrm{~h}$. Similar to the effect of NFKB overexpression on endogenous USP16 mRNA levels (Fig. 5a), stimulation of LPS resulted in a marked 


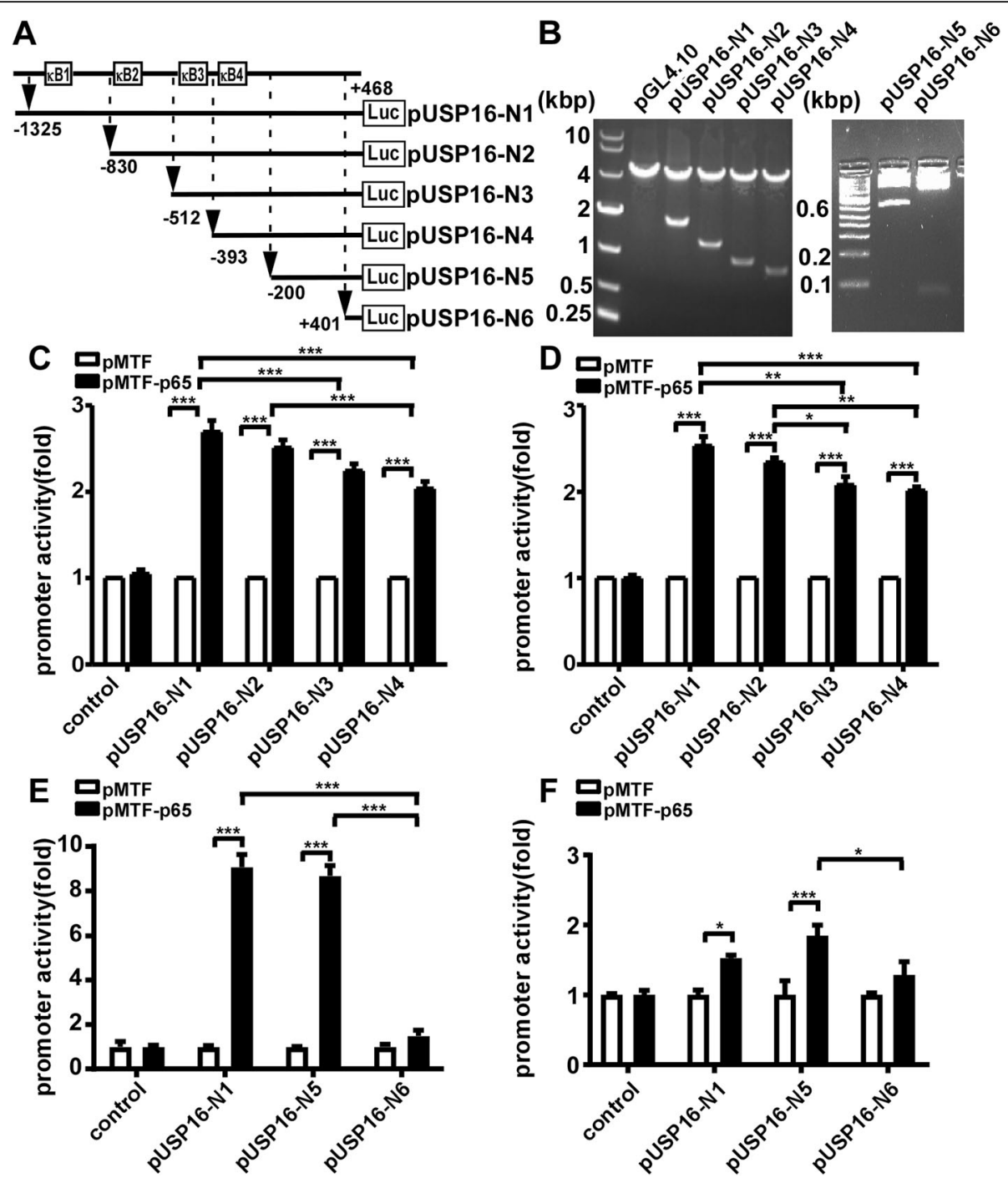

Fig. 3 USP16 promoter activity is up-regulated by NFKB p65. (a) Schematic diagram of deletion plasmids containing different human USP16 promoter fragments in front of the firefly luciferase reporter gene of the pGL4.10 vector. (b) The deletion plasmids corresponding to pUSP16-N1, $-\mathrm{N} 2,-\mathrm{N} 3,-\mathrm{N} 4,-\mathrm{N} 5$ and $-\mathrm{N} 6$ were checked by sequencing and restriction enzyme digestion and the digested samples were analyzed on $1 \%$ or $3.5 \%$ agarose gels. Vector size is $4.2 \mathrm{~kb}$ and the USP16 promoter fragment insert size ranges from $69 \mathrm{bp}$ to $2.2 \mathrm{kbp}$. USP16 promoter deletion plasmids and pMTF-p65 or pMTF were co-transfected into (c, e) HEK293 cells and (d, f) SH-SY5Y cells with pGL4.10 as a control. After transfection for $24 \mathrm{~h}$, the cells were harvested and luciferase activity was presented in relative luciferase units (RLU). The pCMV-Luc luciferase activity was used to normalize for transfection efficiency. The values represent means \pm SEM. $\mathrm{n}=3,{ }^{*} p<0.05,{ }^{* *} p<0.01,{ }^{* * *} p<0.001$ by two-way ANOVA followed by post-hoc Turkey's multiple comparisons test

increase of endogenous USP16 mRNA levels in SH-SY5Y cells (1.55-fold, $p=0.0364$ ) (Fig. 5b), but no significant effect in HEK293 cells (data not shown). However, TNF $\alpha$ enhanced the levels of endogenous USP16 mRNA both in HEK293 cells (1.90-fold, $p=0.0011$ ) (Fig. 5c) and SHSY5Y cells (1.85-fold, $p=0.0327)$ (Fig. $5 \mathrm{~d})$. In order to confirm p65 directly mediating the effect of TNF $\alpha$ on upregulating USP16 transcription, TNF $\alpha$ was further applied to a p65 knockout fibroblast cell line (MEF) and USP16 mRNA levels were examined. As shown in Fig. 5e and f, endogenous USP16 mRNA levels was significantly decreased to 0.65 folds by knocking out p65 in MEF cells $(p=0.0397)$, suggesting $\mathrm{p} 65$ is a strong activator for endogenous USP16 gene expression. Furthermore, TNF $\alpha$ treatment significantly increased USP16 mRNA levels by 1.12 folds compared with control $(p<0.0001)$, whereas such increasement was abolished in MEF p65 KO cells. These data suggest that activation of $\mathrm{NFK}_{\mathrm{K}} \mathrm{B}$ signaling pathway by p65, LPS and TNFa upregulates USP16 gene transcription. Taken together, endogenous USP16 gene transcription was enhanced by activators of the NFKB pathway, including LPS and TNF $\alpha$, and p65 knockout 


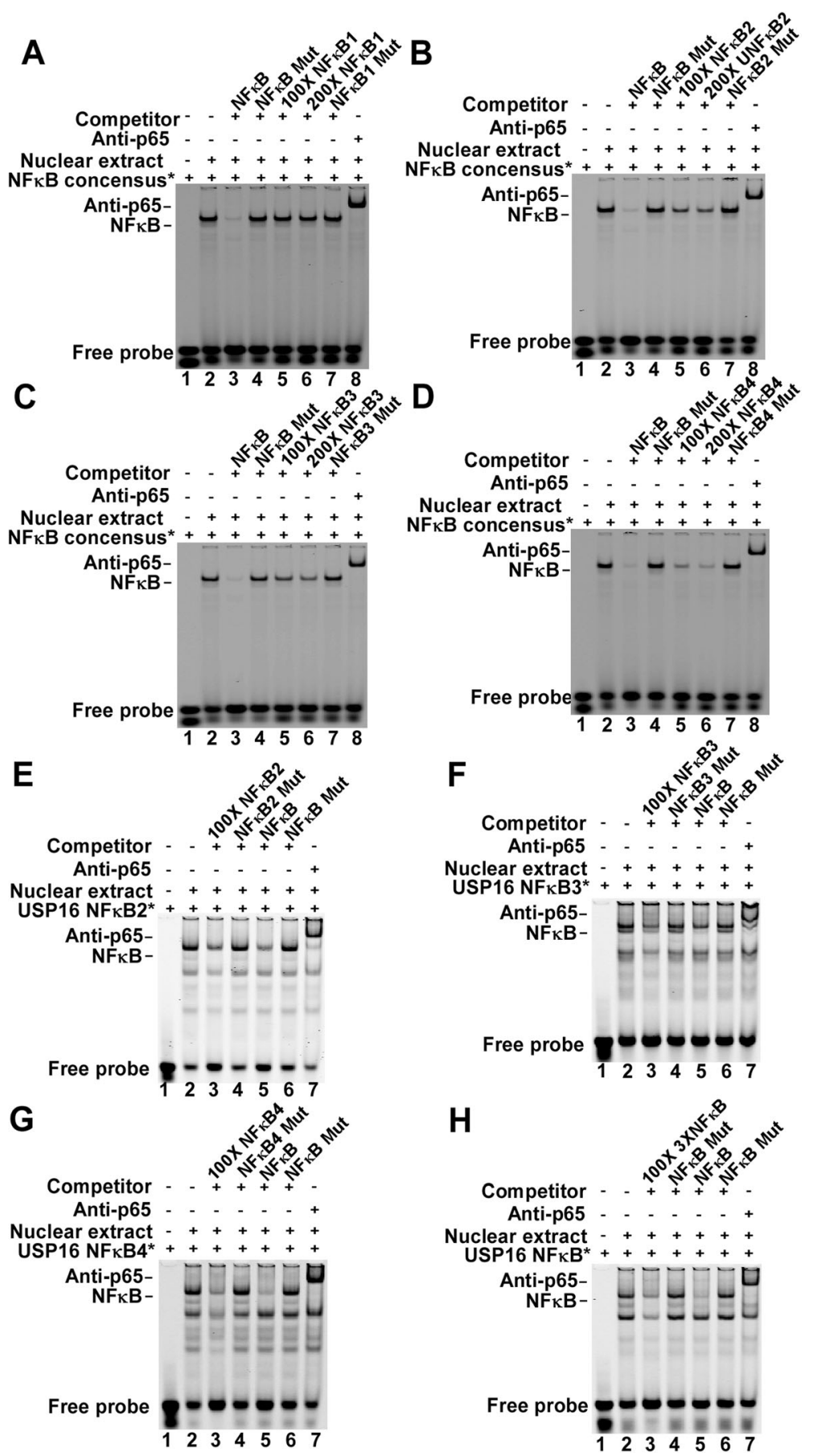

Fig. 4 Gel mobility shift assay for the USP16 gene promoter. Gel shift and Super gel shift assays were performed as described in the Materials and methods. a-d Double-stranded consensus NFKB oligonucleotides were end-labeled with IR700 dye as probes. Incubation of labeled probe with nuclear extracts formed a shifted DNA-protein complex band (lane 2). For competition assays, different concentrations of unlabeled competition oligonucleotides, consensus NFKB (lanes 3), mutant NFKB (lanes 4), USP16 NFkB (lanes 5 and lanes 6), USP16 NFkB mutant (lanes 7) were added. Anti-NFKB p65 antibody was used for the super gel shift assay. Addition of the anti-NFKB p65 antibody into the reaction mixture produced a supershifted band, indicating the formation of the nuclear protein-USP16-p65 complex (lane 8). e-g USP16 NFkB2, USP16 NFkB3, and USP16 NFkB4 double-stranded oligonucleotides were end-labeled with IR700 dye as probes, respectively. Incubation of labeled probe with nuclear extracts formed a shifted DNA-protein complex band (lane 2). For competition assays, unlabeled competition oligonucleotides, USP16 NFKB (lanes 3), USP16 NFKB mutant (lanes 4), consensus NFKB (lanes 5), mutant NFKB (lanes 6) were added. Anti-NFkB p65 antibody was used for the super gel shift assay. The anti-NFKB p65 antibody supershifted the nuclear protein-USP16-p65 complex (lane 7). $\mathbf{h}$ A double-stranded oligonucleotide contains USP16 NFKB2, USP16 NFKB3, and USP16 NFKB4 cis-elements were end-labeled with IR700 dye as probe for EMSA 

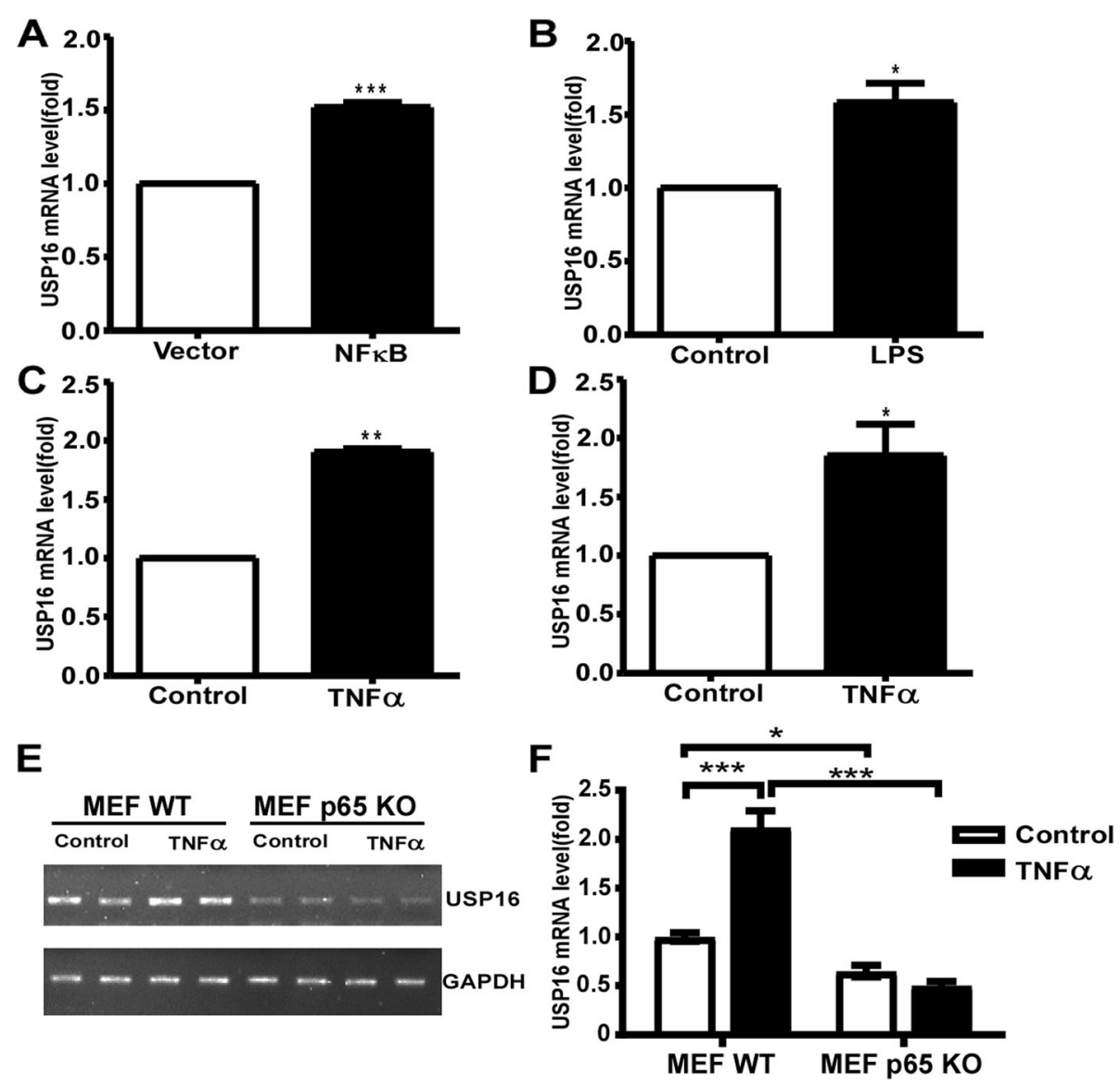

Fig. 5 Enhancement of USP16 transcription in response to p65, LPS and TNFa. (a) HEK293 Cells were transfected with either empty vector (pMTF) or the p65 expression plasmids (pMTF-p65) for $24 \mathrm{~h}$, and USP16 mRNA levels were determined by qRT-PCR. (b) SH-SY5Y cells were exposed to LPS at $50 \mathrm{ng} / \mathrm{ml}$ for $24 \mathrm{~h}$. Total RNA was extracted. The mRNA levels of USP16 were determined by qRT-PCR and normalized against the levels of GAPDH. HEK293 cells (c) and SH-SY5Y cells (d) were exposed to TNFa at $10 \mathrm{ng} / \mathrm{ml}$ for $24 \mathrm{~h}$. The mRNA levels of endogenous USP16 gene were determined by qRT-PCR and normalized against the levels of GAPDH. All data are presented as mean \pm SEM. $n=3$, ${ }^{*} p<0.01$, by analysis of variance with Student's t-test. MEF WT and p65 KO cells (e) were exposed to TNFa at $5 \mathrm{ng} / \mathrm{ml}$ for $24 \mathrm{~h}$, and mRNA levels of USP16 and GAPDH were examined by RT-PCR. (f) The endogenous mRNA levels of USP16 were normalized against the levels of GAPDH and analyzed by two-way ANOVA test followed by post-hoc Turkey's test. The values represent means \pm SEM. $n=3$, ${ }^{* * *} p<0.001$

abolished the effects of TNF $\alpha$ on upregulating USP16 gene transcription.

\section{Discussion}

USP16 protein is a histone H2A-specific deubiquitinase with the coding gene located on human chromosome 21. Several previous studies suggest that it plays many roles in gene expression, cell cycle progression, cell self-renewal, and senescence pathways [17, 18]. USP16 affects hematopoiesis and hematopoietic stem cell function [20]. In mouse hematopoietic stem cells (HSCs), knock out of USP16 was associated with a reduction of mature and progenitor cell populations, while HSC number did not change. USP16 was reported to be involved in hepatocellular carcinoma and decreased expression of USP16 by carboxyl-terminal truncated $\mathrm{HBx}(\mathrm{Ct}-\mathrm{HBx})$ in live tumor cells promoted stem-like properties [22]. By using DS model mice (Ts65Dn), triplication of USP16 contributed to neuronal progenitor defects and abnormal development of mammary epithelium. Overexpression of USP16 in human fibroblast cultures manifested growth impairment and senescence, reminiscent of DS's cells [17]. Additionally, USP16 was shown to interact with HERC2 to regulate ubiquitin signaling during DNA repair during DNA damage response. This could be essentially important to DS, since cellular response to DNA damage was altered in DS patient cells [19].

In this study, we demonstrated that NFkB enhanced human USP16 gene transcription. We first identified that the $5^{\prime}$ flanking region of USP16 gene, from -1856 bp to $+468 \mathrm{bp}$, showed promotor activity. Then we found several functional regulatory elements by a series of promotor deletion analysis. By using a computer- 
based analysis, we determined four putative NFkB binding sites in the promotor region. After conducting EMSA, we provided solid evidence to support that three binding sites (USP16 NFkB2, USP16 NFkB3, and USP16 NFkB4) physically interacts with p65. In this article, we first proved that p65 overexpression could enhance endogenous USP16 mRNA levels through three cis-acting elements. It was unexpected that the promoter activity of the pUSP16-N5 plasmid without any putative p65 binding site was still increased by 065 overexpression. It has been suggested that DNA-binding specificities are different among various $\mathrm{NF} K \mathrm{~B}$ dimers, which is linked to dimer-specific roles in gene regulation [41]. It was reported by a previous study that one c-Rel subunit was able to bind to a nonconsensus half-site of the DNAbinding domain with the other subunit anchoring at the consensus half-site [40]. Therefore, it is possible that a non-canonical NFKB binding site is located in pUSP16$\mathrm{N} 5$, which was regulated by other NFKB family members except p65. As LPS and TNF $\alpha$ are strong activators of NFKB pathway, we tried stimulate USP16 gene by adding LPS and TNF $\alpha$ to cell culture medium and confirmed that both LPS and TNF $\alpha$ stimuli enhanced USP16 transcription. By knocking out p65 in MEF cells, the effects of TNF $\alpha$ treatement on upregulating USP16 gene expression was abolished.

DS has been associated with early onset and higher incidence of aging-related diseases such as $\mathrm{AD}[5,42,43]$. DS patients develop early-onset AD (EOAD). Full trisomy of chromosome 21 inevitably causes the development of two pathological characteristics in AD brains, amyloid plaques and neurofibrillary tangles (NFTs). And by the age of 60 , approximately two-thirds of individuals with DS suffer from dementia [44, 45]. The mechanisms linking $\mathrm{DS}$ to $\mathrm{AD}$ remain to be defined. It has been shown that the aging process is related with an impaired or exhausted ability of stem cells to renew themselves. USP16, in this case, may play a role in AD-related pathogenesis in DS. A number of genes on the chromosome 21 plays an important role in the AD pathogenesis. Duplication of amyloid $\beta$ precursor protein (APP) gene was reported to cause autosomal dominant early-onset Alzheimer disease in five families [46], and various mutations in the APP gene has been identified in AD patients [47]. Our lab recently discovered that BACE2, another the chromosome 21-located gene, was a conditional BACE1 to facilitate AD pathogenesis [48]. NFKB signaling has been implicated in the $\mathrm{AD}$ pathogenesis. BACE1 cleaves APP to generate amyloid $\beta$ protein $(A \beta)$, a central component of neuritic plaques in the $A D$ brains. Previously we found that NFkB p65 expression resulted in increased BACE1 promoter activity and BACE1 transcription [23]. We also demonstrated that non-steroidal anti-inflammatory drugs (NSAIDs) and inhibition of GSK3 signaling inhibited BACE1 transcriptional activation [23, 24]. Regulator of Calcineurin 1 (RCAN1) gene, a gene on Chromosome 21, has been implicated in pathogenesis of DS and AD [49]. We showed that RCAN1 expression was elevated in DS and AD, and its overexpression in primary neurons induced caspase-3 dependent apoptosis $[3,7,8]$. We demonstrated that the RCAN1 isoform 4 gene transcription was activated by NFkB signaling [50]. As we have demonstrated that NFKB promotes USP16 gene transcription in this study, we attempt to explore the role of USP16 in AD pathogenesis in future studies.

Although we have identified that USP16 gene transcription was positively affected by $\mathrm{NF \kappa B}$, we also found three negatively regulatory elements in the USP16 promotor region $(+427 \mathrm{bp} \sim+468 \mathrm{bp},+130 \mathrm{bp} \sim+150 \mathrm{bp},-200 \mathrm{bp} \sim$ $-99 \mathrm{bp}$ ). These three negatively regulatory regions contain a common transcription factor binding site for YY1 (data not shown). The ubiquitous transcription factor YY1 is known to be a multifunctional protein that can either activate or repress gene expression depending upon the cellular context. Ying Yang 1 has been reported to play fundamental roles in embryogenesis, differentiation, replication, and cellular proliferation [51-54]. Ying Yang 1 involved in nervous system development, neuronal differentiation and function [55]. Further studies about whether YY1 could regulate USP16 gene transcription and the potential impacts of USP16 on DS pathogenesis may be warranted.

In conclusion, our study demonstrates that that USP16 gene expression is tightly regulated at transcription level. $\mathrm{NF} \kappa \mathrm{B}$ signaling regulates the human USP16 gene expression through three cis-acting elements. The results provide novel insights into a potential role of dysregulation of USP16 expression in Alzheimer's dementia in Down Syndrome.

\section{Supplementary information}

Supplementary information accompanies this paper at https://doi.org/10. 1186/s13041-019-0535-3.

\section{Additional file 1. Supplementary Information.}

\begin{abstract}
Abbreviations
AD: Alzheimer's disease; DS: Down syndrome; NFkB: Nuclear factor kappa-light-chain-enhancer of activated B cells; USP16: Ubiquitin specific peptidase 16
\end{abstract}

\section{Acknowledgements}

N/A.

\section{Authors' contributions}

WS conceived and designed the experiments; SY, JW, SG, DH and IBL performed the experiments; SY, SG, DH, JW, XN, DL, YL, ML, YK, WZ and WS analyzed and contributed reagents /materials /analysis tools; SY, SG, JW, WZ and WS wrote the paper. All authors reviewed the manuscript. 


\section{Funding}

This work was supported by grants from the Canadian Institutes of Health Research (CIHR) Grant TAD-117948 (W.S) and National Natural Science Foundation of China (NSFC) Grant 81070269, 81571338 (W.Z.). W.S. is the holder of the Tier 1 Canada Research Chair in Alzheimer's Disease.

\section{Availability of data and materials}

Described in Results and Methods section and the authors agree the availability upon request.

\section{Ethics approval and consent to participate}

N/A

\section{Consent for publication}

N/A

\section{Competing interests}

The authors declare that they have no competing interests.

\section{Author details}

'Chongqing City Key Lab of Translational Medical Research in Cognitive Development and Learning and Memory Disorders, and Ministry of Education Key Lab of Child Development and Disorders, Children's Hospital of Chongqing Medical University, Chongqing 400014, China. ${ }^{2}$ Townsend Family Laboratories, Department of Psychiatry, The University of British Columbia, 2255 Wesbrook Mall, Vancouver, BC V6T 1Z3, Canada.

\section{Received: 23 June 2019 Accepted: 11 December 2019}

Published online: 30 December 2019

\section{References}

1. Jacobs PA, Baikie AG, Court Brown WM, Strong JA. The somatic chromosomes in mongolism. Lancet. 1959:1(7075):710.

2. Lejeune J, Gautier M, Turpin R. Study of somatic chromosomes from 9 mongoloid children. C R Hebd Seances Acad Sci. 1959;248(11):1721-2.

3. Sun X, Wu Y, Chen B, Zhang Z, Zhou W, Tong Y, Yuan J, Xia K, Gronemeyer $H$, Flavell RA, et al. Regulator of calcineurin 1 (RCAN1) facilitates neuronal apoptosis through caspase-3 activation. J Biol Chem. 2011;286(11):9049-62.

4. Sun $X$, Wu $Y$, Herculano B, Song W. RCAN1 overexpression exacerbates calcium overloading-induced neuronal apoptosis. PLoS One. 2014;9(4): e95471.

5. Sun X, He G, Song W. BACE2, as a novel APP theta-secretase, is not responsible for the pathogenesis of Alzheimer's disease in Down syndrome. FASEB J. 2006;20(9):1369-76.

6. Sun $X$, Tong $Y$, Qing $H$, Chen $\mathrm{CH}$, Song W. Increased BACE1 maturation contributes to the pathogenesis of Alzheimer's disease in Down syndrome. FASEB J. 2006;20(9):1361-8.

7. Wu Y, Deng Y, Zhang S, Luo Y, Cai F, Zhang Z, Zhou W, Li T, Song W. Amyloid-beta precursor protein facilitates the regulator of calcineurin 1mediated apoptosis by downregulating proteasome subunit alpha type-5 and proteasome subunit beta type-7. Neurobiol Aging. 2015;36(1):169-77.

8. Wu Y, Song W. Regulation of RCAN1 translation and its role in oxidative stress-induced apoptosis. FASEB J. 2013;27(1):208-21.

9. Liu F, Zhang Y, Liang Z, Sun Q, Liu H, Zhao J, Xu J, Zheng J, Yun Y, Yu X, et al. Cleavage of potassium channel Kv2.1 by BACE2 reduces neuronal apoptosis. Mol Psychiatry. 2018;23(7):1542-54.

10. Yun Y, Zhang Y, Zhang C, Huang L, Tan S, Wang P, Vilarino-Guell C, Song W, Sun $X$. Regulator of calcineurin 1 is a novel RNA-binding protein to regulate neuronal apoptosis. Mol Psychiatry. 2019. https://doi.org/10.1038/s41380019-0487-0

11. Arron JR, Winslow MM, Polleri A, Chang CP, Wu H, Gao X, Neilson JR, Chen $L$, Heit JJ, Kim SK, et al. NFAT dysregulation by increased dosage of DSCR1 and DYRK1A on chromosome 21. Nature. 2006:441(7093):595-600.

12. Liu H, Wang $P$, Song W, Sun X. Degradation of regulator of calcineurin 1 (RCAN1) is mediated by both chaperone-mediated autophagy and ubiquitin proteasome pathways. FASEB J. 2009:23(10):3383-92.

13. Wu Y, Ly PT, Song W. Aberrant expression of RCAN1 in Alzheimer's pathogenesis: a new molecular mechanism and a novel drug target. Mol Neurobiol. 2014;50(3):1085-97.

14. Liu X, Wang Z, Wu Y, Wang J, Song W. BACE2 degradation mediated by the macroautophagy-lysosome pathway. Eur J Neurosci. 2013;37(12):1970-7.
15. Busciglio J, Yankner BA. Apoptosis and increased generation of reactive oxygen species in Down's syndrome neurons in vitro. Nature. 1995; 378(6559):776-9.

16. St George-Hyslop PH, Tanzi RE, Polinsky RJ, Haines JL, Nee L, Watkins PC, Myers RH, Feldman RG, Pollen D, Drachman D, et al. The genetic defect causing familial Alzheimer's disease maps on chromosome 21. Science. 1987;235(4791):885-90.

17. Adorno M, Sikandar S, Mitra SS, Kuo A, Nicolis Di Robilant B, Haro-Acosta V Ouadah Y, Quarta M, Rodriguez J, Qian D, et al. Usp16 contributes to somatic stem-cell defects in Down's syndrome. Nature. 2013;501(7467):380-4.

18. Joo HY, Zhai L, Yang C, Nie S, Erdjument-Bromage H, Tempst P, Chang C, Wang $\mathrm{H}$. Regulation of cell cycle progression and gene expression by $\mathrm{H} 2 \mathrm{~A}$ deubiquitination. Nature. 2007:449(7165):1068-72.

19. Zhang $Z$, Yang $H$, Wang $H$. The histone $H 2 A$ deubiquitinase USP16 interacts with HERC2 and fine-tunes cellular response to DNA damage. J Biol Chem. 2014;289(47):32883-94.

20. Gu Y, Jones AE, Yang W, Liu S, Dai Q, Liu Y, Swindle CS, Zhou D, Zhang Z, Ryan TM, et al. The histone H2A deubiquitinase Usp16 regulates hematopoiesis and hematopoietic stem cell function. Proc Natl Acad Sci U S A. 2016;113(1):E51-60.

21. Yang $W$, Lee $Y H$, Jones $A E$, Woolnough $J$, Zhou D, Dai Q, Wu Q, Giles KE, Townes TM, Wang H. The histone H2A deubiquitinase Usp16 regulates embryonic stem cell gene expression and lineage commitment. Nat Commun. 2014:5:3818.

22. Qian $Y$, Wang B, Ma A, Zhang $L, X u$ G, Ding $Q$, Jing T, Wu L, Liu Y, Yang Z, et al. USP16 Downregulation by carboxyl-terminal truncated HBx promotes the growth of hepatocellular carcinoma cells. Sci Rep. 2016;6:33039.

23. Chen $\mathrm{CH}$, Zhou W, Liu S, Deng Y, Cai F, Tone M, Tone Y, Tong Y, Song W. Increased NF-kappaB signalling up-regulates BACE1 expression and its therapeutic potential in Alzheimer's disease. Int J Neuropsychopharmacol. 2012;15(1):77-90.

24. Ly PT, Wu Y, Zou H, Wang R, Zhou W, Kinoshita A, Zhang M, Yang Y, Cai F, Woodgett J, et al. Inhibition of GSK3beta-mediated BACE1 expression reduces Alzheimer-associated phenotypes. J Clin Invest. 2013;123(1):224-35.

25. Wang K, Liu S, Wang J, Wu Y, Cai F, Song W. Transcriptional regulation of human USP24 gene expression by NF-kappa B. J Neurochem. 2014:128(6):818-28.

26. Lawrence T. The nuclear factor NF-kappaB pathway in inflammation. Cold Spring Harb Perspect Biol. 2009;1(6):a001651.

27. Morgan MJ, Liu ZG. Crosstalk of reactive oxygen species and NF-kB signaling. Cell Res. 2011;21(1):103-15.

28. Barkett M, Gilmore TD. Control of apoptosis by Rel/NF-kappaB transcription factors. Oncogene. 1999:18(49):6910-24.

29. Baldwin AS. The NF-kappa B and I kappa B proteins: new discoveries and insights. Annu Rev Immunol. 1996;14:649-83.

30. Baeuerle PA, Baltimore D. I kappa B: a specific inhibitor of the NF-kappa B transcription factor. Science. 1988;242(4878):540-6.

31. Baeuerle PA, Henkel T. Function and activation of NF-kappa B in the immune system. Annu Rev Immunol. 1994;12:141-79.

32. Alkalay I, Yaron A, Hatzubai A, Orian A, Ciechanover A, Ben-Neriah Y Stimulation-dependent I kappa B alpha phosphorylation marks the NFkappa B inhibitor for degradation via the ubiquitin-proteasome pathway. Proc Natl Acad Sci U S A. 1995;92(23):10599-603.

33. Joyce D, Albanese C, Steer J, Fu M, Bouzahzah B, Pestell RG. NF-kappaB and cell-cycle regulation: the cyclin connection. Cytokine Growth Factor Rev. 2001;12(1):73-90.

34. Salminen A, Kauppinen A, Kaarniranta K. Emerging role of NF-kB signaling in the induction of senescence-associated secretory phenotype (SASP). Cell Signal. 2012;24(4):835-45.

35. Janssens $\mathrm{S}$, Tschopp J. Signals from within: the DNA-damage-induced NFkappaB response. Cell Death Differ. 2006;13(5):773-84.

36. Takase O, Yoshikawa M, Idei M, Hirahashi J, Fujita T, Takato T, Isagawa T, Nagae $G$, Suemori $H$, Aburatani $H$, et al. The role of NF-IÊB signaling in the maintenance of pluripotency of human induced pluripotent stem cells. PLoS One. 2013;8(2):e56399.

37. Liu S, Zhang S, Bromley-Brits K, Cai F, Zhou W, Xia K, Mittelholtz J, Song W. Transcriptional regulation of TMP21 by NFAT. Mol Neurodegener. 2011;6:21.

38. Feng Y, Li X, Zhou W, Lou D, Huang D, Li Y, Kang Y, Xiang Y, Li T, Zhou W, et al. Regulation of SET gene expression by NFkB. Mol Neurobiol. 2017:54(6): 4477-85.

39. Lott IT, Head E. Alzheimer disease and Down syndrome: factors in pathogenesis. Neurobiol Aging. 2005;26(3):383-9. 
40. Sanjabi S, Williams KJ, Saccani S, Zhou L, Hoffmann A, Ghosh G, Gerondakis S, Natoli G, Smale ST. A c-Rel subdomain responsible for enhanced DNA-binding affinity and selective gene activation. Genes Dev. 2005;19(18):2138-51.

41. Hoffmann A, Natoli G, Ghosh G. Transcriptional regulation via the NFkappaB signaling module. Oncogene. 2006;25(51):6706-16.

42. Sun X, Wang Y, Qing H, Christensen MA, Liu Y, Zhou W, Tong Y, Xiao C, Huang $Y$, Zhang $S$, et al. Distinct transcriptional regulation and function of the human BACE2 and BACE1 genes. FASEB J. 2005;19(7):739-49.

43. Zigman WB, Lott IT. Alzheimer's disease in Down syndrome: neurobiology and risk. Ment Retard Dev Disabil Res Rev. 2007;13(3):237-46.

44. McCarron M, McCallion P, Reilly E, Mulryan N. A prospective 14-year longitudinal follow-up of dementia in persons with Down syndrome. J Intellect Disability Res. 2014;58(1):61-70.

45. Zigman WB, Schupf N, Urv T, Zigman A, Silverman W. Incidence and temporal patterns of adaptive behavior change in adults with mental retardation. Am J Ment Retard. 2002;107(3):161-74.

46. Rovelet-Lecrux A, Hannequin D, Raux G, Le Meur N, Laquerriere A, Vital A, Dumanchin C, Feuillette S, Brice A, Vercelletto M, et al. APP locus duplication causes autosomal dominant early-onset Alzheimer disease with cerebral amyloid angiopathy. Nat Genet. 2006;38(1):24-6.

47. Hunter S, Brayne C. Understanding the roles of mutations in the amyloid precursor protein in Alzheimer disease. Mol Psychiatry. 2018;23(1):81-93.

48. Wang Z, Xu Q, Cai F, Liu X, Wu Y, Song W. BACE2, a conditional betasecretase, contributes to Alzheimer's disease pathogenesis. JCI Insight. 2019; 4(1):e123431.

49. Wu Y, Zhang S, Xu Q, Zou H, Zhou W, Cai F, Li T, Song W. Regulation of global gene expression and cell proliferation by APP. Sci Rep. 2016;6:22460.

50. Zheng L, Liu H, Wang P, Song W, Sun X. Regulator of calcineurin 1 gene transcription is regulated by nuclear factor-kappaB. Curr Alzheimer Res. 2014;11(2):156-64.

51. Affar el B, Gay F, Shi Y, Liu H, Huarte M, Wu S, Collins T, Li E, Shi Y. Essentia dosage-dependent functions of the transcription factor yin yang 1 in late embryonic development and cell cycle progression. Mol Cell Biol. 2006; 26(9):3565-81.

52. Hwang SS, Jang SW, Kim MK, Kim LK, Kim BS, Kim HS, Kim K, Lee W, Flavell RA, Lee GR. YY1 inhibits differentiation and function of regulatory T cells by blocking Foxp3 expression and activity. Nat Commun. 2016;7:10789.

53. Palko L, Bass HW, Beyrouthy MJ, Hurt MM. The yin Yang-1 (YY1) protein undergoes a DNA-replication-associated switch in localization from the cytoplasm to the nucleus at the onset of S phase. J Cell Sci. 2004;117(Pt 3):465-76.

54. Vella P, Barozzi I, Cuomo A, Bonaldi T, Pasini D. Yin Yang 1 extends the Mycrelated transcription factors network in embryonic stem cells. Nucleic Acids Res. 2012;40(8):3403-18.

55. He Y, Casaccia-Bonnefil P. The yin and Yang of YY1 in the nervous system. J Neurochem. 2008;106(4):1493-502.

\section{Publisher's Note}

Springer Nature remains neutral with regard to jurisdictional claims in published maps and institutional affiliations.

Ready to submit your research? Choose BMC and benefit from:

- fast, convenient online submission

- thorough peer review by experienced researchers in your field

- rapid publication on acceptance

- support for research data, including large and complex data types

- gold Open Access which fosters wider collaboration and increased citations

- maximum visibility for your research: over $100 \mathrm{M}$ website views per year

At $\mathrm{BMC}$, research is always in progress.

Learn more biomedcentral.com/submissions 